\title{
Complications of Instrumental Vaginal Deliveries and Associated Factors in Suhul General Hospital, Shire, North-West Tigray, Ethiopia
}

\section{Solomon Gebre ${ }^{1^{*}}$ and Assefa Hailu ${ }^{2}$}

${ }^{1}$ Mearg General Hospital, Emergency Surgical Department, Dansha, West Tigray, Ethiopia

${ }^{2}$ Freweyni Primary Hospital, Emergency Surgical Department, Freweyni, Eastern Tigray, Ethiopia

*Corresponding author: Solomon Gebre, Mearg General Hospital, Emergency Surgical Department, Dansha, West Tigray, Ethiopia, Tel: 251911366834; Email:solomunlka@yahoo.com; solomongebre300gmail.com

Received date: March 20, 2017; Accepted date: March 31, 2017; Published date: April 07, 2017

Copyright: (C) 2017 Gebre S, et al. This is an open-access article distributed under the terms of the Creative Commons Attribution License, which permits unrestricted use, distribution, and reproduction in any medium, provided the original author and source are credited.

\begin{abstract}
Instrumental vaginal delivery is a key element of essential obstetric care, and scaling up its use in resource poor countries through training and supply of appropriate equipment is likely to contribute significantly to reduce maternal and newborn morbidity and mortality and objective of the study was to assess complications of instrumental vaginal delivery and associated factors. A two years retrospective cross sectional analytical study was conducted from July 2013 to June 2015 in the obstetric department of Shire, Suhul General Hospital, North-West zone, Tigray Ethiopia. Records of 357 mothers managed with operative vaginal delivery were retrieved, $224(62.7 \%)$ were rural residents. Low instrumental vaginal delivery was the most common type of practiced station $(208,58.3 \%)$ but mid instrumental delivery is highly associated with complications [AOR 95\% Cl $12.2(4.79-31,4)$ ]. Fetal distress was the most common indication of operative vaginal deliveries, $158(44.3 \%)$ as well as the commonest cause of low $1^{\text {st }}$ minute Apgar score, 97 (54.8\%). More than half of mothers were assisted with forceps, $187(52.4 \%)$, and it was the, commonest cause for perineal tear (67.4\%) and significantly associated with feto maternal complications [AOR 95\% Cl 1.73 (1.07-2.80)]. Even though forceps had higher maternal complications, vacuum extraction has higher fetal complications. We conclude that obstructed labor (OL), mid pelvic instrument application, increases in birth weight and forceps application were significantly associated with feto maternal complications.
\end{abstract}

Keywords: Instrumental vaginal delivery; Forceps; Vacuum

\section{Introduction}

The first instrumental deliveries were performed to extract fetuses from parturients who were at high risk of maternal mortality due to prolonged and/or obstructed labor. In these cases, saving the mother's life took weighs over possible harm to the fetus. The focus of these procedures has changed as a result of modern obstetrical practices that have drastically reduced the risk of intra partum maternal mortality and major morbidity. Decisions regarding use of instrumental delivery are now based primarily upon the fetal/neonatal impact of these procedures and are weighed against the alternative options of cesarean birth [1].

Instrumental vaginal delivery is a key element of essential obstetric care, scaling up its use in resource poor countries through training and supply of appropriate equipment is likely to contribute significantly to reduce maternal and newborn morbidity and mortality [2]. Obstetrical care providers frequently face dilemmas in the management of the second stage of labor. The decision as to whether or not a particular birth requires assistance and the choice and timing of any intervention must involve consideration of the risks of the potential techniques and the skills of the operator, as well as the urgency of the need to expedite the birth process [3].

Maelmstrom's device eventually received international acceptance in the middle of the $20^{\text {th }}$ century. He first introduced his device in 1953. Maelmstrom is therefore credited as the father of the modern vacuum extractor [4]. In recent years, the success rate for operative vaginal deliveries has been quite high (99\%). This likely reflects appropriate choice of candidates for this intervention. However, the wide range of operative vaginal delivery rates (1\%-23\%), both across and within geographic regions in the United States, suggests that evidence based guidelines for operative vaginal delivery are either inadequate or randomly applied [5].

In the past, shortening the second stage was an acceptable option, independent of any specific maternal or fetal indications, because early studies suggested the risk of fetal morbidity was higher when the second stage of labor exceeded two hours. More recent evidence does not support this practice. The ability of fetal heart rate monitoring to identify the fetus who is not tolerating labor has generally made the arbitrary termination of labor because of any elapsed period of time unwarranted [6].

Improving Maternal Health is often called "The heart of the MDGs," because if it fails, the other MDGs will fail as well [7,8]. Many countries have made significant progress in expanding and improving maternal health care services. However, discrepancies continue to exist in accessing to maternal health care between high and low income countries, the rich and poor, urban and rural, [9]. Although fetal and maternal outcome depends on the quality of care starting from preconception, the big chunk of it is relied on timely and appropriately carried out intra partum care. One of the big advancement of modern medicine is the ability to prevent the causes of perinatal and maternal mortality. Unfortunately, $98 \%$ of perinatal and maternal deaths occur in low income countries. At present, one woman in 12 will die of maternal causes in Sub-Saharan Africa, compared with one woman in 4000 in northern Europe with perinatal mortality rates of 10 per 1000 live births $[10,11]$. 
Results from the 2011 EDHS data show a remarkable decline in all levels of childhood mortality in Ethiopia. Infant mortality has declined by $42 \%$ over the 15 -year period preceding the Survey from 101 deaths per 1,000 live births to 59 deaths per 1,000 live births. Furthermore, under-five mortality has declined by 47 percent over the same period from 166 deaths to 88 deaths per 1,000 live births. Even though not to the same extent, neonatal mortality has also decreased over the 15-year period preceding the survey by $31 \%$ from 54 deaths to 37 deaths per 1,000 live births. The estimated maternal mortality ratio is almost the same in the 2011 EDHS (676) as it was in the 2005 EDHS (673). Thus, there is no evidence to suggest that the maternal mortality ratio decreased in Ethiopia between 2000 and 2011 [12]. To reduce the mortality ratio, one of the life-saving services is providing emergency obstetric care at least starting from the health center level. Basic emergency obstetric care (BEOC) is proposed to be delivered at a health center level, whereas comprehensive emergency obstetric care is planned to be carried out at the district hospital level [13]. Emergency obstetric operative interventions (caesarean section and instrumental delivery), in conjunction with other life support measures, are considered to be instrumental to avert perinatal as well as maternal deaths [3,6]. However, assisted vaginal delivery is one of the underutilized and least available basic signal functions in resource poor countries Unmet training needs, lack of suitable equipment and human resource shortages are some reasons for this. In many resource poor settings vacuum extraction is performed only by medical doctors who may only be regularly available in large urban hospitals [14]. Even though IVD in important and has a place in modern obstetrics to decrease maternal and perinatal mortality, complications can happen which can cause maternal and fetal morbidity and mortality. This two year review will analyze the Magnitude and types of complications of instrumental vaginal deliveries (IVD) and to determine associated factors.

\section{Material and Methods}

This was a two years retrospective cross sectional analytical study was conducted from July 2013 to June 2015 in the obstetric department of Shire, Suhul General Hospital, North- West zone, Tigray Ethiopia.

\section{Result}

\section{Socio demographic characteristics and obstetric characteristics}

Of the 403 mothers managed with instrumental vaginal delivery, 46 mothers were excluded because of incomplete charts and lost cards, 33 and 13 cards, respectively. Two hundred twenty four mothers (62.7\%) were from rural areas of the referral catchment area of the hospital. The mean age of the study subjects was $23.8 \pm 5.1$ years. About two-third, $244(68.3 \%)$, were waiting their first baby. More than three fourth, (78.7\%), born to a mother underwent instrumental delivery were term whereas $26(7.3 \%)$ new born were preterm and nearly nine-tenth of the mothers, 311 (87.1\%), had ANC follow up. 246 (68.9\%) of instrumental deliveries were applied to a fetus in OA position, 3.2 Indication and mode of delivery of instrumental vaginal delivery. In the study period low instrumental delivery is common 208 (58.3\%) followed by out let and mid pelvis instrumental deliveries, $28.6 \%$ and $13.2 \%$ respectively. Fetal distress was the most common indication, 160 (44.3\%) and Forceps assisted vaginal delivery was also frequently used instrumental delivery, 197 (55.2\%) than vacuum.

\section{Feto-maternal complications}

In the study period nearly half of instrumental vaginal delivery (45.4\%) was complicated, of this maternal complication takes the lead, accounts for 97 (59.8\%). Perineal tear was the leading maternal complication, 90 (92.7\%) and low Apgar score recorded as commonest fetal complication ( $83 \%$ of all fetal complications). Low $1^{\text {st }}$ minute Apgar score is recorded in 184 neonates delivered by IVD in the study period. Of which fetal distress was the commonest indication (53.2\%), but there was no difference between forceps and vacuum use. Second degree perineal tear accounts for more than half of the perineal tears $(63 \%)$ and one case of uterine rapture was observed.

\section{Determinants of feto-maternal complication}

Mothers who residue in rural area were nearly two times higher to develop feto maternal complication than the urban residents (COR $1.58,95 \% \mathrm{CI}=1.02-2.44)$. Application of high instrumental vaginal delivery (station above 2) and low instrumentation are having fetomaternal complication than out let instrumental delivery (COR 7.4, $95 \%=3.28-16.6$ and COR 1.55, 95\% CI=0.94-2.55) respectively. Among the indications IVD applied for Obstructed labor (OL) were highly associated significantly with feto-maternal complication than mothers underwent IVD for other indications. Factors like parity, Gestational age, ANC, fetal position and maternal age were not associated with complication. On the other hand fetal weight, type of instrument and indication of instrumental delivery were significantly associated with complications.

\section{Discussion}

In Suhul Hospital, in the study period, Two hundred eight (58.3\%) instruments were low forceps, whereas $28.6 \%$ and $13.2 \%$ was out let and mid pelvic operative deliveries. IVD has been done for OP and OT positions other than OA (95, (26.6\%), 15, (4.2\%) and $247(69.2 \%)$ respectively). Two hundred forty four $(68.3 \%)$ mothers managed by operative vaginal delivery were expecting their first baby. Most authors have reported primigravida with untested pelvis has high rate of OVD. This is supported by previous studies done in USA (72\%, Nigeria (78.6\%), and Addis Ababa (86.2\%) [15-17]. Forceps assisted delivery was found the commonest mode of operative vaginal deliveries, which accounts for $52.4 \%$ followed by vacuum extraction (44.5\%) and forceps application two times increases feto-maternal complication (COR,95\% CI 1.63 (1.06-2.48)and AOR,95\% CI 1.73 (1.07-2.80). This finding was inconsistent with studies done in countries like Ireland, England, Canada and Australia that shows higher rates of vacuum than forceps, this may be due to withdrawal of using forceps delivery in developing countries due to serious complications [18-21].

Fetal distress was the most indication of instrumental deliveries, $44.3 \%$ and commonest cause of low 1st minute Apgar score (54.8) $[3,22,23]$. But mothers with OL has highly associated with feto maternal complications (COR, 95\% CI 15 (1.93-116.3), AOR, 95\% CI, 17 (1.96-148.3). This finding is inconsistent with other studies [14,24-27], this may be explained by the low prevalence of OL in other countries. This Forceps delivery has been found having higher maternal complications that accounts for $44 \%$ of maternal complications and $75 \%$ of perennial tear. Of the perennial tears $71.4 \%$ of $2^{\text {nd }}$ and $3^{\text {rd }}$ degree was associated with forceps delivery. In line with other studies. Forceps delivery is relatively higher maternal complications [16,20,25,26-28]. Application of mid pelvis instrument has higher rate of maternal complications $66 \%$ of $3^{\text {rd }}$ degree perineal 
Citation: Gebre S, Hailu A (2017) Complications of Instrumental Vaginal Deliveries and Associated Factors in Suhul General Hospital, Shire, North-West Tigray, Ethiopia. J Gen Pract (Los Angel) 5: 300. doi:10.4172/2329-9126.1000300

Page 3 of 3

tear and $60 \%$ of shoulder dystocia and associated with over all complications(COR 95\% CI, 7.40 (3.26-16.64) and AOR 95\% CI, 12,2 (4.79-31.41) $\mathrm{P}=0.000[29,30]$.

\section{Conclusion and Recommendation}

\section{Regional health and at district level}

In our study we found that most of the study subjects were come from areas far more from Suhul hospital and all of the perinatal deaths and most of the maternal and fetal complications are totally preventable if the training of health professionals in management emergency obstetric complications is properly established. And we recommend that continuous training of health workers and fulfilling equipment's used for instrumental delivery at the referring unit is mandatory.

\section{Suhul hospital}

Even though larger studies are needed to establish the likely association and significance, we conclude that obstructed labor (OL), mid pelvic instrument application, birth weight and forceps application were significantly associated with feto-maternal complications. Then discussion to minimize those practices and clear facility based indications and pre request should available.

\section{Stake holders}

Giving short and long term trainings and preparing resources for instrumental deliveries.

\section{References}

1. Martin JA, Hamilton BE, Ventura SJ, Osterman MJ, Kirmeyer S, et al. (2009) Births: final data for Natl Vital Stat Rep.

2. Sunday E, Adaji, Ameh CA (2016) Operative Vaginal Deliveries in Contemporary Obstetric Practice; from Preconception to postpartum, Dr. Stavros Sifakis (Ed.). InTech 255-266.

3. Cunningham FG, Leveno KJ, Bloom SL, Hauth JC, Rouse DJ, et al. (2010) Williams Obstetrics. (23rd edtn). New York, USA.

4. Johanson R, Menon V (2000) Soft versus rigid vacuum extractor cups for assisted vaginal delivery. Cochrane Database Syst Rev 2: CD 000446.

5. Clark SL, Belfort MA, Hankins GD, Meyers JA, Houser FM (2007) Variation in the rates of operative delivery in the United States. Am J Obstet Gynecol 196: 526.e1.

6. (2000) American College of Obstetricians and Gynecologists. Guidelines at a Glance: Operative vaginal delivery ACOG Practice Bulletin number 17, American College of Obstetricians and Gynecologists, Washington, DC, USA.

7. (2007) Family care International. Women deliver for development, London. 18-20.

8. (2000) Central statistic Authority Ethiopia: Demographic \& Health Survey.

9. (1996) UNICEF. Progress on maternal mortality, Geneva.
10. Donnay F (2000) Maternal survival in developing countries: What has been done, what can be achieved in the next decade. Int. J Gynaecol Obstet 70: 89-97.

11. (1996) WHO, Family and Reproductive Health: Perinatal mortality: A listing of available Information.

12. (2012) Central statistic Authority Ethiopia: Demographic \& Health Survey.

13. Maine D, Akalin MZ, Ward VM, Kamara A (1997) The design and evaluation of maternal mortality programs. Center for population and family health, School of public health, Columbia University 19-21.

14. Fauveau, V (2006) Is vacuum extraction still known, taught and practiced A worldwideKAP survey, International J Gynaecol Obstet 94: 185-189.

15. Adaji SE, Shittu SO, Sule ST (2009) Operative vaginal deliveries in Zaria, Nigeria. Ann Afr Med 8: 95-99.

16. Demissie K, Rhoads GG, Smulian JC, Balasubramanian BA, Gandhi K, et al. (2004) Operative vaginal delivery and neonatal and infant adverse outcomes: population based retrospective analysis. BMJ 329: 24-29.

17. Kiros K, Lakew Z (2006) Magnitude of episiotomy in a teaching hospital in Addis Ababa, Ethiopia. Ethiop Med J 44: 205-209.

18. (2003) Vacca, A. Handbook of vacuum delivery in obstetric practice, Australia, Vacca Research.

19. Ali UA, Norwitz ER (2009) Vacuum-assisted vaginal delivery. Rev Obstet Gynecol 2: 5-17.

20. Prapas N, Kalogiannidis I, Masoura S, Diamanti E, Makedos A, et al. (2009) Operative vaginal delivery in singleton term pregnancies: Shortterm maternal and neonatal outcomes. Hippokratia 13: 41-45.

21. Lumbiganon $P$, Laopaiboon $M$, Gülmezoglu AM, Souza JP, Taneepanichskul S, et al. (2010) Method of delivery and pregnancy outcomes in Asia: The WHO global survey on maternal and perinatal health 2007-08. Lancet 375: 490-499.

22. Yifru B, Ahmed A (2004) Emergency Obstetric Performance with emphasis on operative delivery outcome: Does it reflect the quality of care? Ethiop J Health Dev 18: 96-106.

23. Wen SW, Liu S, Kramer MS, Marcoux S, Ohlsson A, et al. (2000) Comparison of Maternal and Infant Outcomes between Vacuum Extraction and Forceps Deliveries: American J of Epidemiology 153: 2.

24. Kadas A, Aliyu L, Hauwa M (2011) Instrumental vaginal delivery in bauchi, northeast Nigeria. J West Afr Coll Surg 1: 18-27.

25. Lawani LO, Anozie OB, Ezeonu PO, Iyoke CA (2014) Comparison of outcomes between operative vaginal deliveries and spontaneous vaginal deliveries in southeast Nigeria. Int J Gynaecol Obstet 125: 206-209.

26. (2011) Instrumental vaginal delivery clinical practice guide line from the French collage of Obstetrics and gynecology, Europ. J Obstet. Gynec. Reprod. Biol 159 43-48.

27. Johanson RB, Menon V (2000) Vaccum extraction vs. forceps for assisted vaginal delivery Cochrane Database Syst Rev 2: CD000224.

28. Lewis T, DaCosta V, Harriott J, Wynter S, Christie L, et al. (2011) Factors related to Obstetrics 3rd and 4th degree perineal tear in Jamaica Cohort, West Indian Med. J. v 60.

29. Decherney AH, Nathan L, Goodwin TM, Laufer N (2007) Current Diagnosis and Treatments in Gynecology and Obstetrics. (10th edtn). McGraw- Hill Companies, USA.

30. Gibbs RS, Karlan BY, Haney AF, Nygaard IE (2008) Dan forth's Obstetrics and Gynecology. (10th edtn). Lippincott Williams \& Wilkins, USA. 